\title{
The Medallion (Spherical) Shape Vessels of Islamic Period Known as Fogha Jars from the Morphological Point of View
}

\author{
Morteza Garavand ${ }^{1}$, Somayeh Kazemi Dehaghi*2, Moloud Sadat Azimi²
}

1. Dept. of of Archeology, Tehran University, Tehran, Iran

2. Research Center for Conservation of Cultural Relics (RCCCR), Tehran, Iran

\begin{abstract}
Article Info
Received: 2017/05/25

Accepted: 2017/07/28

Published Online 2017/10/29

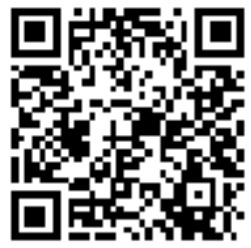

Ir Cons Sci J

2017; 1(1): 39-47

ABSTRACT

The medallion (Spherical) shape ceramic vessels, known as Fogha jars date back tc early Islamic centuries. Theses ceramics are ordinary unglazed vessels, yet clearly distinct from other unglazed ceramics, in terms of their shape and formation and are easily detectable. These vessels have been discovered in the ancient sites of many Islamic countries including Iran, Egypt, Mesopotamia, Syria as well as Spain and India The medallion (Spherical) shape ceramics are completely backed and have a compac texture to the extent that they are not easy to break. In fact, the vessel's body is very thick compare to their size and this makes them very heavy as well. The structures anc the compounds of this type of ceramics, discovered in the cultural layers of severa sites, are not still clear; therefore, a comprehensive study on these ceramics not only requires the cultural and archeological knowledge but also the physical and chemica analyses. Regarding the cultural significance of the mentioned ceramics and theis unique features, the present study aims in studying these medallion (Spherical) shap ceramic vessels by means of precise scientific criteria and high standards. To this aim after the general description of the ceramics, their physical and chemical propertie: were also evaluated by means of several laboratory methods and analytical devices ir order to reach a morphological perspective of the ceramics in terms of theis components, techniques and methods of manufacturing. The samples were analyzec via XRF elemental analysis and X-ray photography to identify the types of compound: and the firing technique. The physical features are also evaluated via hardness, density porosity tests etc.
\end{abstract}

Keywords: Ceramic, Medallion (Spherical) Shape Ceramics, Fogha jar, Archeologica survey, XRF analysis, X-ray Analysis

\footnotetext{
Corresponding Information: Somayeh Kazemi Dehaghi.Research Center for Conservation of Cultural Relics (RCCCR), Tehran, Iran. Email: s.kazemi@richt.ir
}

Copyright @ 2017, Ir Cons Sci J. This is an open-access article distributed under the terms of the Creative Commons Attribution-noncommercial 4.0 International License which permits copy and redistribute the material just in noncommercial usages, provided the original work is properly cited.

\section{Introduction}

Ceramics are the most featured materials in the archeological studies and due to their abundance, they are reliable evidences to trace the cultural and social trends of a society. Unlike some other fields of art, the art of pottery continued to develop even after the Islamic period in Iran and it is probably due to the Islam's emphasis on simple life and not utilizing golden and silver vessels. The medallion (Spherical) shape ceramics known as Fogha jars are one of the most magnificent samples of Islamic pottery and can be considered as the Alchemy art of the Islamic pottery. These ceramics have a thick body and narrow mouth, decorated with carving or applied decorations or patchwork. One of the distinctive features of these ceramics is their hardness which makes them totally unique from other types of Islamic pottery. Through a comprehensive knowledge about the features of these specific ceramics, many problems concerning their manufacturing techniques can be resolved and clarified. Therefore, after the general description of the ceramics, their physical and chemical properties are also evaluated by means of several laboratory methods and analytical devices in order to reach a morphological perspective of the ceramics in terms of their components, techniques and method of preparation. The samples were analyzed via XRF elemental analysis and X-ray photography to identify the types of compounds and the manufacturing techniques. The physical features are also 
evaluated by means of hardness, density, porosity tests etc.

\subsection{Overview of medallion (Spherical) shape ceramics (Fogha Jars)}

Regarding the purpose of the present study in identifying the technical features of these ceramics, the laboratory studies were utilized. Consequently, a summary of the current theories and hypothesis from the archeological and the Iranian literature points of view are also presented about the functional concepts, chronology and the nature of these vessels during Islamic period and their usages in the Iranian culture.

"Fogha was a non-alcoholic carbonated soft beverage which was being kept in the small jars and people were drinking it for refreshment and quenching their thirst" (PourJavadi, 1988; Sadeqi, 2001). According to Dehkhoda Dictionary, "Fogha was a carbonated nonalcoholic beverage being kept in heavy jars and their mouth was tightly covered with a skin, the jar was covered with ice in order to keep the drink cool; a hole was being made in the skin once they wanted to drink the liquid and Fogha was coming out through the pressure of the gas inside" (Dehkhoda, 1998). The Pahlavi equivalence of Fogha is also mentioned in three different sources including the Culture of Pahlavi, Kār-Nāmag $\overline{1}$ Ardašīr i Pābagān (Book of the Deeds of Ardeshir, Son of Papak) and Draxt $\overline{1}$ Āsūrīg (The Assyrian Tree) as "Vashak" or "Vashk" which means Fogha but the containing material is not mentioned (Henning, 1995). In fact, Fogha was originally used as a cool beverage in hot places like the pottery workshops (Fig $1 \& 2$ ), beside the kilns, bath houses or special ceremonies. As it was mentioned before, these medallion vessels known as Fogha jars are discovered all over the Islamic lands and their neighboring areas from Fostat in Egypt to the shores of Volga River in Russia (Ali Youssef, 1982; Ettinghausen, 1965). The remains of this type of ceramic have been also discovered in several sites in Iran such as Nishapur, Takht-e Soleiman, Gorgan, Susa, Sultaniye and Rey.

These vessels have a short neck and a tight mouth and there is a convex or chamfer bottom on their base which makes their stability hard or impossible. These ceramics are ordinary and unglazed, completely backed with a dense and hard texture. They come in different sizes, forms, diameter, thickness and height depending on their functions. Some of them are so big that it is impossible to hold them in one hand while in some cases they can fit in one hand (Fig 1). Most of them are decorated with flowers, cruciform, geometric, plant and animal motifs, almond shape patterns, carved horizontal or vertical lines and Kufic inscriptions, in some cases they are decorated with patchwork designs (Fig.2). Besides the importance of these vessels in the archeological studies, they have been frequently mentioned in the literary sources and poets mentioned their forms and functions in their works which multiples the value of this type of pottery.

Albolfazl Habish described this ceramic as "a medallion vessel with a thin base and mouth" (Habish, 1957); Ibn Battuta also mentioned the ceramics, "the guests started eating and the Fogha jars were brought after the meal ... no one shared a plate and Fogha would be served in ceramic flasks after the meal and the pilgrims (Haji) were raising their glasses saying the name of God while drinking" (Ibn Battuta, 1997). The name of this vessel is also mentioned by Ferdowsi, the Iranian poet, as he presented his masterpiece, Shahname, to the king and faced the ingratitude of Sultan Mahmud of Ghazni. When he presented a copy of Shah Name to the court of Sultan Mahmud of Ghazni, king was not very pleased with the work and did not reward the poet a worthy price. According to Nizami Aruzi, Ferdowsi granted his twenty thousand dirham reward to the bathhouse and to the Fogha sales. He meant to show that the king's reward did not worth of the masterpiece which took thirty years of his life (Pour Javadi, 1988). Ferdowsi later composed a satire regarding this event:

$$
\begin{aligned}
& \text { به קاداش گنج مرادر گشاد } \\
& \text { به من جز بهاى فقاعى نداد } \\
& \text { فقاعى نيرزيدم از حنج شاه } \\
& \text { از آن من فقاعى خريدم براه }
\end{aligned}
$$

(He took my treasure and gave nothing but a penny to get a drink- I did not worth more than that from the treasures of the king and so I bought a Fogha on my way)

Majireddin Beylaqani, the poet during the $6^{\text {th }}$ century AH mentioned the form of the Fogha jars as the following:

$$
\text { شكم مشو همه جون كوزه فقاع زحرص در خور ترياقها شوى سداب }
$$

(Do not make your belly rounded like a Fogha jar out of avidity etc.)

In fact, the concept of Fogha was being used as a meaningful and powerful irony by Iranian poets and writers which has been totally forgotten. The term, Fogha, was used in several works during the fifth and sixth centuries while after the Mongol invasion, its utilization in the literature was reduced until its total disappearance in the $8^{\text {th }}$ century (PourJavadi, 1988). Interestingly the absence of this term in the literature was associated with the absence of the object in the archeological sites and excavations. 


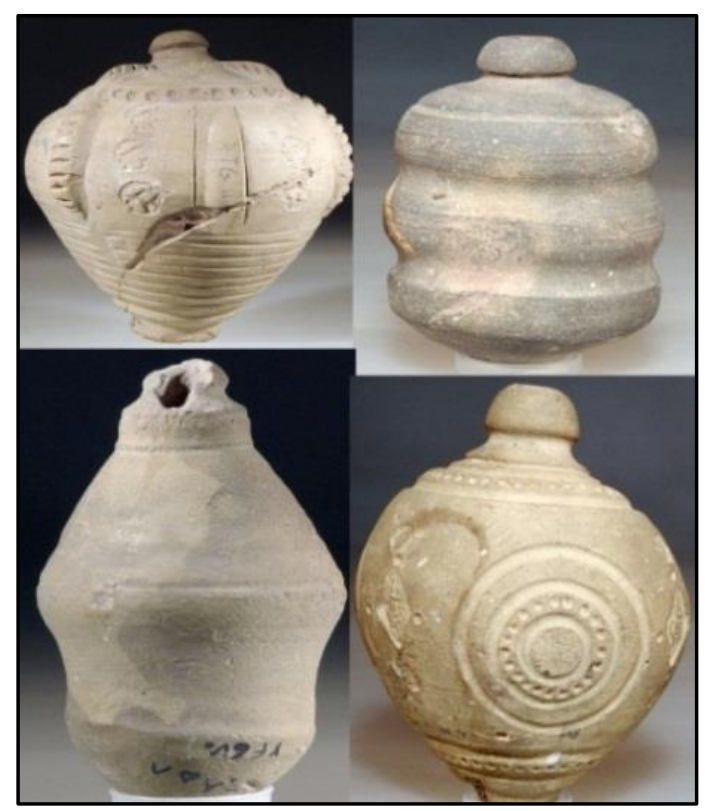

Fig 1.

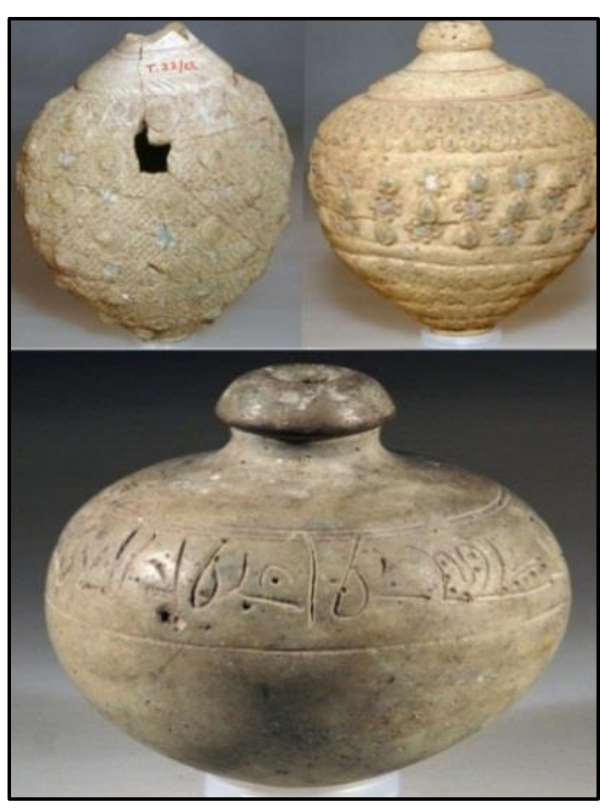

Fig 2.
Many diverse hypotheses are proposed regarding the use and function of these specific vessels, yet reaching a unified opinion is hard due to the lack of evidences about the function of this cultural material and numerous theories and hypotheses. A great number of sherds and intact vessels including the Fogha jars or the medallion vessel were discovered in the residential and industrial sections of an ancient site in Nishapur through an excavation by the American team with the supervision of Wilkinson. He believed that this vessels were used to store valuable liquids such as rose water or as a water sprinkler for washing hands before eating (Wilkinson, 1973). He also mentioned the discovery of the same type of vessels date back to the $9^{\text {th }}$ century in Oren-Kala and Baila Qan in Azerbaijan with an inscription saying "Drink to your goodwill" which revealed the function of this vessel as a beverage container. Later he changed his theory about the vessel as a container into a multifunctional vessel (Ibid, 1987). Jacque believes that these vessels were also used as the oil purifier or a grenade (Jacque, 1974), He continues with this justification that the Inca tribes were using oil for making explosions, since during the Spanish invasion in America they encountered the first oil refinery composed of a number of small vessels containing oil, as they were laid them in the sun and sun heat would separate the pure oil. It has been also said that Arabs were using grenades against Saint Louis during the Crusades wars. During the $8^{\text {th }}$ century AD Arabs were putting oil in grenades and throwing them at their enemies (Ibid, 1974). According to Zafar Heydar, these vessels were used as hand grenades in the battle fields, soldiers were pouring gunpowder inside them and threw them toward the enemy after lighting the wick up. Some of these conical or pomegranate shape grenades with rough body and pointed base are discovered around Rawalpindi (Haider, 1991). According to Quchani, these ceramics were Fogha jars, yet they were used for other purposes as well (Quchani, 1987). Regarding their common usage in the Fogha sales, they have been discovered in abundance around the pottery kilns where they were produced. In an archeological excavation in Takht-e Soleiman in 2005, a bath house related to Ilkhanid period was discovered which was surrounded with great number of ceramic sherds of Fogha containers, this discovery suggest the utilization of this vessel in public places like bathhouses (Moradi, 2004). To sum up, the discovery of these vessels in different sites has caused the researchers to propose different hypotheses about their functions such as Fogha jar (crock), grenade, Huqqah-i-Atish (fire trick), bottle, mercury container, censer, pilgrim bottles for containing the holy water or simply known as the sphere conical vessel.

However, given the various shapes of these vessels, it is not possible to assume a single function for them; but through literary references and studying the archeological data from different sites, many different functions are assumable for them, yet more field studies and laboratory analyses are required to reach a more comprehensive conclusion.

\subsection{Technology of the Ceramics}

Ceramics are produced by means of processing and firing the clay which is abundant on the earth. This material is the result of thousand years of severe erosion 
of igneous rocks and metamorphic rocks such as granite. The most common way to categorize the soil is based on their origin, so that there are two types of clay: the primary clay deposit beside the parent material and remains there. These type of soils are pure as they do not mixed with other minerals, their sources are the stones eroded through contact with surface water, steam and gases. They are found as irregular veins in rocks. The other clay type is the secondary or the sedimentary clay which are transferred to other places after the decomposition of the main stones and are more abundant than the first type. The secondary clay contain more impurities like Iron, Quartz, mica as well as organic materials (Basiri, 1984: 23-24).

\subsection{Elemental analysis and its application in archeology}

"Clay deposits are mostly composed of aluminum silicate and different other components, are plastic and formable due to their water content and become hard, brittle and non-plastic upon drying or g. although the hardened clay can get soft by getting wet, but the produced and backed ceramics are quite durable and can survive for centuries" (Blinderit, Conservation and restoration artwork and historical monuments, 1997: 400). "Although the raw clays are generally composed of alkaline aluminum silicates, but they greatly differ in the chemical compositions and the nature and quantity of impurities and that is the reason for the variety of different ceramics with different qualities. In fact, depends on the temperature, backing time, using oxygen or not, the quality and the physical feature of the ceramics may differ" (Ibid: 409). However, the physical changes do not influence the combining elements.

Therefore, the elemental analysis of the discovered cultural material by means of the laboratory methods is possible and thus, identifying the probable source of the ceramics is conceivable by means more examination and laboratory tests. Generally, the application of the system of elemental analysis in archeology and restoration include the following:

- The qualitative and quantitative analysis of the mineral and organic elements to evaluate the technology of the artifacts.

- Identifying the amount of the trace elements in the artifacts to determine their origins and authenticity.

- The qualitative and quantitative analysis of the containing elements of the artifacts in terms of the erosion and corrosion process as well as analyzing the discovered kilns in the ancient sites.

\subsection{The essentiality of the elemental analysis}

The elemental analyses are conducted on the ceramics discovered in Nishpour, Takht-e Soleiman and Rey from the Islamic sites. Due to the lack of evidences and data in terms of their production techniques, hardness and color, these ceramics were chosen as the subject of this study. Regarding the results of the similar studies on other historical and prehistorically periods and also in other sites in Iran and abroad, the following research questions are proposed:

1. Were these ceramics produced in a specific area and exported to other regions?

2. Were the production of these ceramics required specific knowledge of the containing materials from the potter and did they have their special methods in according to the regional material?

3. Identifying the production manufacturing techniques of these ceramics is possible through their elemental analysis.

4. Regarding the previously mentioned discussion about the elemental analysis and as the chemical features of the coil do not change through time, conducting the elemental analysis on the samples seems essential in order to answer the research questions and researching the precise scientific results.

\section{Studying the ceramics}

\subsection{Primary studies (physical characteristics)}

The primary studies of the ceramics' physical characteristics include their color, hardness, porosity etc. other features such as the nature of the raw material for the body and glazing, backing temperature, manufacturing techniques, environmental factors such as soluble salts, extreme climate changes were also being checked and analyzed. The final purpose of these studies were to determine the technical characteristics of the ceramics, coverage or lack thereof, soil gradation, temper and the backing quality (Fig. 3).

\subsubsection{Hardness measurement}

Hardness means abrasion resistance and the strength and durability to resist damage and erosion. The hardness measurement are normally categorized based on the Mohs table. So that the hard material scratch softer material. Table 1 represents the hardness degree of seven studied samples based on the Mohs table. 

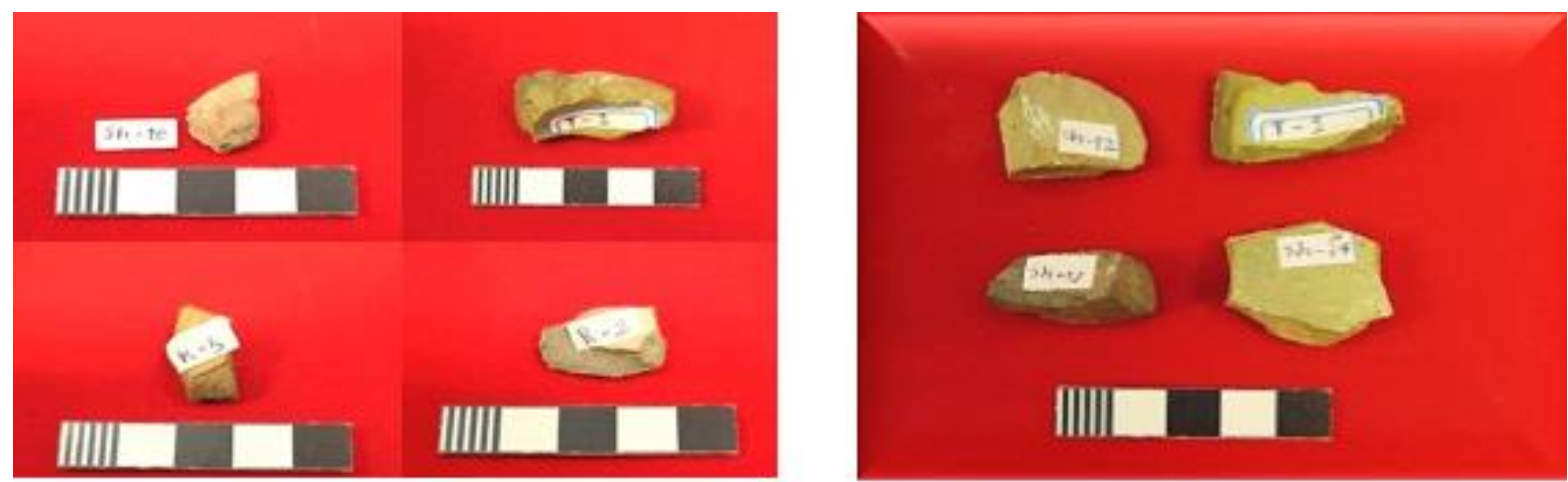

Fig 3. The studied samples

Table.1. The hardness degree of the ceramics based on the Mohs table

\begin{tabular}{rcc} 
No. & Sample & Hardness \\
\hline 1 & F1 & 6 \\
2 & F2 & 6 \\
3 & F3 & 7 \\
4 & F4 & 6 \\
\hline 5 & F5 & 7 \\
\hline 6 & F6 & 6 \\
\hline 7 & F7 & 6 \\
\hline
\end{tabular}

The prominent features of this ceramics are their density and hardness. It seems that the clay is well kneaded so that there are no more air bubbles inside the clay and the result is a dense and hard material for producing the ceramics. However, ceramics' hardness depends on other factors such as the temperature of the kiln, impurities of the clay, grain size and density of the clay, temper and the aeration kiln.

\subsubsection{The Porosity Percentage}

Determining the voids is also a technical examination on the ceramic' body. The amount of voids and their frequency is a very important point in studying the quantity of the ceramics. Porosity is having minute interstices through which liquid or air may pass and the ratio of pore volume to the total volume of sample. For instance a ceramics with high porosity has higher ability to absorb water and Therefore lower resistance to environmental factors such as pressure, temperature shock, freezing etc.

According to this method which is based on the evaluation of the weight and volume, the volume sample is once measured when it is dried and once measured when it is saturated and the difference between the two parameters is the mass of empty space (cavity).

Water density at $40^{\circ} \mathrm{C}$ is equal to 1 so that this parameter can be the pore volume. Table 2 represents the porosity degree of seven studied samples.

Table.2. Porosity Percentage

\begin{tabular}{cccccc} 
No. & Sample & Dried sample weight & Saturated sample weight & The apparent volume & Porosity Percentage \\
\hline 1 & F1 & 8.40 & 8.45 & 4.50 & 11.11 \\
2 & F2 & 5.05 & 5.20 & 2.4 & 16 \\
3 & F3 & 10.35 & 10.70 & 5 & 10 \\
4 & F4 & 6.75 & 7.15 & 3.5 & 14.28 \\
5 & F5 & 6.85 & 6.90 & 3.3 & 9.09 \\
6 & F6 & 2.15 & 2.20 & 1.1 & 09 \\
\hline 7 & F7 & 2.80 & 2.85 & 1 & 09 \\
\hline
\end{tabular}

\subsubsection{Measurement of water absorption}

This experiment is conducted by means of soaking the samples in deionized water with specific temperature and pressure. The amount of absorbed water is a percentage of the dried object which means the amount of absorbed water is measured according to the volume of the dried object through soaking the sample in water and weighing it at predetermined time intervals. In order to obtain optimum results, the samples should be weighted 8 hours before the examination and then each 24 hours so that the amount of the absorbed water in two acceptable weights would not be greater than 0.1 percent of the total volume. Table 3 represents the amount of the water absorption level of the samples.

$\mathrm{M}_{\mathrm{n}}=$ the weight of the soaked sample

$\mathrm{M}_{0}\left(\mathrm{M}_{0}-\mathrm{M}_{\mathrm{n}}\right)=$ water absorption

$\mathrm{M}_{0}=$ the weight of the dried sample 
Table.3. Amount of the water absorption

\begin{tabular}{ccc} 
No. & Ssmple & Water Absorption \\
\hline 1 & F1 & 0.59 \\
2 & F2 & 1.98 \\
3 & F3 & 3.38 \\
4 & F4 & 5.95 \\
5 & F5 & 0.7299 \\
6 & F6 & 2.32 \\
7 & F7 & 1.78 \\
\hline
\end{tabular}

The distinctive feature of clay is its ultrafine particles and their high absorption ability. Once the clay soaks in water, each particle would be covered with a layer of water. Because of the flatness of the particles, water makes them stick together and slip on each other under the pressure so that they are ductile and flexible. The flexibility of the clay depends on the amount of the absorbed water, if the water evaporates, the clay hardens quickly and it would not be ductile anymore. Since a large amount of clay consists of water, with the evaporation of water, the clay volume decreases. The particles' contraction depending on the type of the clay and the size of the particle is between 5 to 7 percent.

\subsubsection{Density}

Density of an object is the representative of the particle density or granulation compaction of the ceramic's body. The density of the objects in certain temperatures is an equal number, as the volume of objects change in proportion to the temperature. Therefore, the density of the object can be estimated by means of measuring the weight of the sample and its proportion with the certain volume. Table 4 represents the density of the samples.

\subsubsection{Other Definitions}

\section{- Strength}

In the primary examinations, apparent durability shows the strength of materials and objects. However, more precise examinations, considering the preservation condition and utilization of the objects, are required by means of measuring the pressure, elasticity and heat resistance as well as the body and glaze resistance against freezing and thawing of water-saturated objects.

Table.4. the density of the samples

\begin{tabular}{cccccc} 
No. & Sample & Dry weight & Saturated weight & Dry density & Saturated density \\
\hline 1 & F1 & 8.40 & 8.45 & 1.86 & 1.87 \\
2 & F2 & 5.05 & 5.20 & 2.10 & 2.16 \\
3 & F3 & 10.35 & 10.70 & 2.07 & 2.14 \\
4 & F4 & 6.75 & 7.15 & 1.92 & 2.04 \\
5 & F5 & 6.85 & 6.90 & 2.07 & 2.09 \\
6 & F6 & 2.15 & 2.20 & 1.95 & 2.85 \\
\hline
\end{tabular}

\section{- Humidity measurement}

Humidity is a physical feature which reveals the soil behavior regarding the body of the ceramics. The changes in moisture content after considerable changes in the volume can lead to cracks, dents etc. in the body.

\subsection{Elemental analysis studies}

\subsubsection{XRF fluorescence spectroscopy}

This semi-quantitative method is used for the elemental analysis which is based on the emission of characteristic "secondary" (or fluorescent) X-rays from a material that has been excited by bombarding with highenergy X-rays or gamma. The phenomenon is widely used for elemental analysis and chemical analysis, particularly in the investigation of metals, glass, ceramics and building materials, and for research in geochemistry, forensic science, archaeology and art objects such as paintings and murals. When materials are exposed to short-wavelength X-rays or to gamma rays, ionization of their component atoms may take place. Ionization consists of the ejection of one or more electrons from the atom, and may occur if the atom is exposed to radiation with an energy greater than its ionization potential. X-rays and gamma rays can be energetic enough to expel tightly held electrons from the inner orbitals of the atom. The removal of an electron in this way makes the electronic structure of the atom unstable, and electrons in higher orbitals "fall" into the lower orbital to fill the hole left behind. In falling, energy is released in the form of a photon, the energy of which is equal to the energy difference of the two orbitals involved. Thus, the material emits radiation, which has energy characteristic of the atoms present. The term fluorescence is applied to phenomena in which the absorption of radiation of a specific energy results in the 
re-emission of radiation of a different energy (generally lower).

Samples can be in the form of powder, solutions, sheets, layers etc; samples usually will not be lost and they can be evaluated after the spectroscopy. Due to the limitation of the X-rays penetration depth, especially in the areas of long wavelengths, the surface layers must be the representative of the whole tested samples. In the other word, the sample must be prepared uniform and homogeneous. This device can identify all of the elements with atomic number higher than 11 and used as a complementary method in addition to other mineralogical methods, such as X-ray diffraction XRD and petrographic.

Clay contains other elements such as titanium oxide, potassium oxide, sodium oxide, magnesium oxide, iron oxide and calcium oxide with different percentages depending on the type of the soil. China clay or kaolin is the major type of the primary clay and in cooperation with the secondary clays has higher gradation and lower plasticity. Its high purity causes its white color after being backed as well as its refractoriness $\left(1750{ }^{\circ} \mathrm{C}\right)$. Table 5 represents the results of the XRF analysis on the samples.
The XRF analysis was conducted on 9 ceramic samples. The results showed that the silicon oxide $\left(\mathrm{SiO}_{2}\right)$ and aluminum $\left(\mathrm{Al}_{2} \mathrm{O}\right)$ are the most abundant elements in the clay with the average of 55.86 and 18.57, respectively. According to the results, there is a direct relation between the existence of silicon dioxide $\left(\mathrm{SiO}_{2}\right)$ and aluminum oxide $\left(\mathrm{Al}_{2} \mathrm{O}\right)$ in the clay and the hardness of the clay, since the high amount of these elements on the clay can led to its hardness and strength after the being well backed. These results are in consistence with the hardness measurements. Table 6 represents the average of the other elements of the body.

Alkaline oxides and Alkaline earth metals such as sodium, potassium, and calcium are functioning as the ceramic fluxes during the backing process. As can be seen from table 6 , the potassium oxide $\left(\mathrm{K}_{2} \mathrm{O}\right)$ with an average of 2.12 and calcium oxide $(\mathrm{CaO})$ with an average of 10.66 are among the other abundant elements in the samples. Therefore, we can conclude that these oxides are the most important ceramic fluxes which increase the amount of lava. A ceramic flux functions by promoting partial liquefaction in clay bodies and glazes.

Table 5. The results of the XRF analysis

\begin{tabular}{cccccccccc} 
& $\mathrm{T} 1$ & $\mathrm{R} 1$ & $\mathrm{R} 2$ & $\mathrm{~K} 5$ & $\mathrm{SH} 10$ & $\mathrm{SH} 11$ & $\mathrm{SH} 12$ & $\mathrm{SH} 13$ & $\mathrm{SH} 14$ \\
$\mathrm{MgO}$ & 10.13 & 8.78 & 8.25 & 5.26 & 8.66 & 7.23 & 9.97 & 9.18 & 7.42 \\
$\mathrm{Al}_{2} \mathrm{O}_{3}$ & 19.74 & 19.36 & 16.95 & 18.56 & 19.43 & 19.27 & 18.2 & 19.08 & 16.62 \\
$\mathrm{SiO}_{2}$ & 55.38 & 55.47 & 48.6 & 52.11 & 57.05 & 58.54 & 58.2 & 58.62 & 58.82 \\
$\mathrm{SO}_{3}$ & - & - & 0.9 & 0.61 & - & - & - & - & - \\
$\mathrm{Cl}$ & - & - & 0.6 & 0.33 & 0.23 & - & - & - & 0.32 \\
$\mathrm{~K} 2 \mathrm{O}$ & 2.02 & 2.14 & 1.62 & 3.28 & 1.92 & 2.07 & 1.96 & 1.9 & 2.2 \\
$\mathrm{CaO}$ & 8.87 & 10.03 & 18.92 & 16.07 & 8.18 & 8.44 & 8.72 & 7.61 & 9.12 \\
$\mathrm{Ti}_{2} \mathrm{O}_{3}$ & 0.36 & 0.37 & 0.36 & 0.36 & 0.43 & 0.4 & 0.31 & 0.37 & 0.47 \\
$\mathrm{Cr}_{2} \mathrm{O}_{3}$ & - & - & - & - & - & - & 0.01 & - & 0.01 \\
$\mathrm{MnO}^{2} \mathrm{Fe}$ & 0.09 & 0.1 & 0.07 & 0.07 & 0.08 & 0.1 & 0.05 & 0.06 & 0.11 \\
\hline $\mathrm{Fe}$ & 3.41 & 3.75 & 3.74 & 3.26 & 4.02 & 3.95 & 2.76 & 3.18 & 4.86 \\
$\mathrm{SrO}$ & - & - & - & 0.09 & - & - & - & - & 0.05 \\
\hline
\end{tabular}

Table 6. The average amount of body's elements

\begin{tabular}{ccc} 
No. & Combination & Average \\
\hline 1 & $\mathrm{MgO}$ & 8.32 \\
2 & $\mathrm{Al}_{2} \mathrm{O}_{3}$ & 18.57 \\
3 & $\mathrm{SiO}_{2}$ & 55.86 \\
4 & $\mathrm{SO}_{3}$ & 0.55 \\
5 & $\mathrm{Cl}$ & 0.16 \\
6 & $\mathrm{~K}_{2} \mathrm{O}$ & 2.12 \\
7 & $\mathrm{CaO}$ & 10.66 \\
8 & $\mathrm{Ti}_{2} \mathrm{O}_{3}$ & 0.38 \\
9 & $\mathrm{MnO}$ & 0.08 \\
10 & $\mathrm{Fe}_{2} \mathrm{O}_{3}$ & 3.63 \\
\hline
\end{tabular}

Fluxes are used in glazes to lower the high melting point of the glass formers silica and boron trioxide. In clay bodies a flux creates a limited and controlled amount of glass, which works to cement crystalline components together. Fluxes play a key role in the vitrification of clay bodies by reducing the overall melting point. The most commonly used fluxing oxides in a ceramic glaze contain lead, potassium, lithium, magnesium, barium, calcium and sodium. The color, hardness, and porosity of ceramics depends on some factors such as the kiln temperature, the aeration and the cooling process after backing the pottery. Ceramics with different colors are being backed in different temperatures, but through controlling the condition and temperature of the kiln can result in various colors of ceramics in the same temperature, thus, deciding about the temperature and the backing style of the ceramic based on its color is not precise. The first step in identifying the kiln temperature 
is determine the type of minerals in the clay so that the thermal decomposition can be used in the next steps.

It seems that the ceramics' colors are obtained by mixing different compounds while the amount of the containing elements and the backing conditions, especially the aeration, are also influential. Other factors effecting the color of the ceramics are the transition metal oxides such as iron oxide, manganese oxide, $\mathrm{ZnO}$, titanium, copper oxide and chromium oxide and some of them in addition to influencing the color of the ceramics are also function as the ceramic flux. For example, despite the equal amount of iron oxide in some ceramics, some of the ceramics have a brighter color than others.

It is worth mentioning that the colors of these elements and their derivatives, or generally the color of a color-producing substance, are not always the same and the environmental conditions are highly effective; the most important factors in this case are: The chemical composition of the surrounding environment of the color producing substance, the kiln and its temperature. For example, chromium compounds react differently in different environments and their derivatives are usually creating the spectrum of green colors in the ceramics.

\subsubsection{X-ray photography}
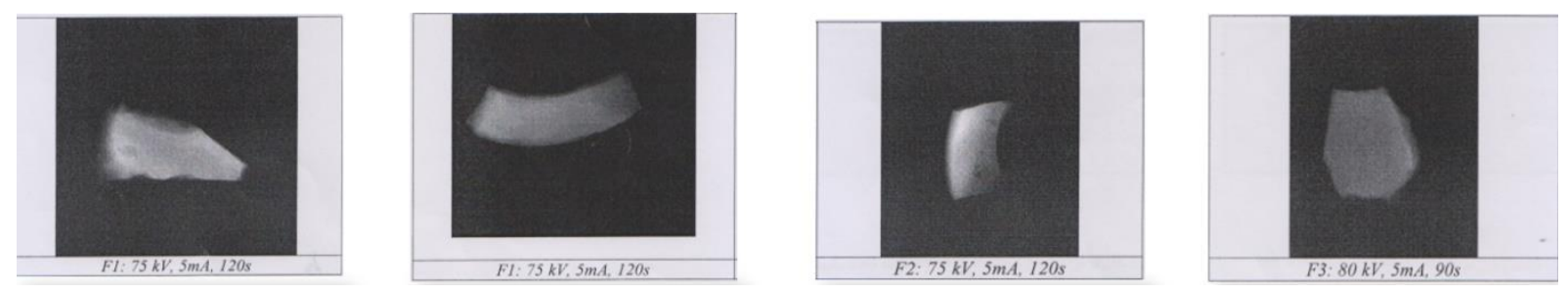

Fig.4. The studied samples

Tempers are non-plastic materials added to clay to prevent shrinkage and cracking during drying and firing of vessels made from the clay, controlling the contraction process of the clay from wet to dry and dry to backed, and function as a skeleton in the mud so that manufacturing fine and fragile ceramics would be possible. Preparing tempers in different regions require different methods but they are normally divided into two general groups of organic tempers (straw and dried herbs) and non-organic tempers (sand, gravel and clay powder), besides, sometimes other materials such as animals' hairs, lie goats, are also added to the temper.

Tempers usually have different melting points and chemical resistance and their main function is preventing the deformation of the ceramics during the firing process, providing appropriate thermal
$\mathrm{X}$-radiations is a form of electromagnetic radiation with shorter wavelength than those of UV rays that reflect the image of an object on a screen sensitive to the radiations. This images have various densities, depending on the X-rays. The X-rays are passing through the empty holes and voids in the object and remain black traces on the screen, however, other parts of the object are also absorbing the radiations and leave more or less brighter traces on the screen depending on their type of material, thickness and density. Various densities are revealing the manufacturing techniques, inner joints, previous restorations and some flaws like the internal cracks and rigidity points. Note that regarding the type, substance, dimensions and thickness of the object as well as the quality of the photography and the interpretation of the captured photo are all very important in providing the final results.

The results of the radiography on 4 samples of the mentioned ceramics showed that all of the samples are made by pottery wheel and some substances such as sand and straw were mixed in their temper. However, the small size of the sherds did not allow us to determine the exact formation method. (Fig. 4) 
ceramics are very thick in comparison with their height which might be due to their function as preserving the temperature of the liquid inside. The first hypothesis regarding the thickness and the shape of the ceramic was that they are made by coiling or molding methods, but the laboratory results reveled that besides the mentioned

\section{References}

Aliyoussof, A. (1982). Studies in the Egyptian pottery: oil bottles (stems). Archaeological Islamic studies. Cairo.

Dehkhoda, A. (1998). Dictionary (2nd Ed.). Tehran University Publication.

Beyləqani, M. (1979). Diwan of Mujiroddin Beylaqani with correction and suspension of Mohamad Abadi Tabriz, the institute of Iranian history and culture, P:24.

Durali, S. \& Bahroullumi, F. (1999). Determining the the baking temperature of the tiles and bricks via XRD and STA. Iranian Journal of Crystallography and Mineralogy. 7(2), 133-144.

Ettinghausen, R. (1965). The uses Sphero-Conical Vessels in the Muslim East. Journal of Near Eastern Studies, XXIV, 218-230.

Haider, S. Z. (1991). Islamic arms and armour of Muslim India. Bahadur Publishers.

Henning, W. B. (1955). The Middle-Persian Word for Beer (pp. 603-604). BSOAS. methods, some of the vessels were made by pottery wheel. Therefore, considering the relatively high hardness and strength of the ceramics, we can assume that viscous and slippery materials were likely added to the temper of the medallion ceramics to facilitate the work of the potter's wheel.

Moradi, Y. (2004). The report of the fourth season on the third series of the archeological excavations in Takht-e Suleiman. The Documentation Center Collection of Takht-e Suleiman (unpublished report).

Movahed, M. (1997). Travelogues of Ibn Battuta (Vol. 1). Agah Publication.

Pourjavadi, N (1988). Opening Fogha: Ferdowsi and then Attar, a Discussion over the nature of the poet and poetry from the point of view of Attar (Vol. 1). Danesh Publication.

Quchani, A. (1987). Fogha Jar. The Journal of Archeology and History. 2 (1), 40- 45.

Roman, J. (1974). The application of Oil and its derivatives in ancient periods. Translated by Masoud Rajabnia. Journal of Art and People. 12 (144), P 38-44.

Sadeqi, A. (2001). The Historical Issues of Persian Language (series of articles). 8 (6) (pp. 38-40). Tehran: Danesh Publication.

Wilkinson, C. K. (1973). Nishapur: pottery of the early Islamic period. Metropolitan Museum of Art.

\section{How to Cite This Article:}

Garavand M, Kazemi Dehaghi S, Azimi M S. The Medallion (Spherical) Shape Vessels of Islamic Period Known as Fogha Jars from the Morphological Point of View. Ir Cons Sci J. 2017; 1(1):39-47

URL: http://journal.richt.ir/ics/article-1-26-en.html 